\title{
What drives scientific integration in Africa? Evidence from publications
}

\author{
Lorenzo Cassi $^{1,3}$, Mafini Dosso ${ }^{2}$, Wilfriedo Mescheba ${ }^{3}$ \\ lorenzo.cassi@univ-paris1.fr. ${ }^{1,3}$, mafini.dosso@ec.europa.eu $^{2}$, wilfriedo.mescheba@, hceres.fr $^{3}$
}

Paris School of Economics University of Paris $1^{1}$

European Commission, Joint Research Centre Seville, Spain ${ }^{2}$ HCERES-OST, Paris, France ${ }^{3}$

\begin{abstract}
Scientific integration is considered as fundamental for the development of an African system of research and innovation (AOSTI 2014, NEPAD 2006). This study exploits copublications data on the period 2000-2015 to discuss the factors driving regional scientific integration in Africa overtime. It argues that a better understanding of the bottom up and regional factors driving the evolution of African scientific collaborations is key to design evidence-informed policies in a globalizing knowledge society.
\end{abstract}

Keywords: scientific collaborations, African countries, publications, bibliometrics, gravity model

\section{Introduction}

Awareness of the importance of scientific cooperation for socio-economic development has led since the years 2000 s to the adoption of several regional and national policy instruments and frameworks in Africa. ${ }^{1}$ Developed in the context of the New Partnership for Africa's Development (NEPAD) and endorsed in 2006, the African Science and Technology Consolidated Plan of Action (CPA) constitutes such a framework. The CPA intended to support, among other, the strengthening of links between science systems and the development of networks of centres of excellence through the thematic flagship programmes (NEPAD 2006). So far, few progresses have been observed outside the agricultural research field, mainly due to the lack of funding, of effective national policy prioritization as well as limited steering capabilities of African Union's (AU) implementation bodies (DIE, 2010). Nonetheless, improvements can be observed both in the quantity and quality of Africa's research output as well as in the regional cooperation (DIE 2010, WB 2014, Dosso et al 2017).

Understanding the existing degree of regional scientific integration in Africa is a key step to design policies aimed at building a common research area in this region, and it represents the main research interest of this study. This is even more relevant as research collaborations in Africa present distinctive features that should be mapped in order to design evidenceinformed policies and policy practices (Adam et al 2014, World Bank 2014). Also, it can reasonably be assumed that the last two decades, marked by fast economic growth and enhanced support to S\&T-related activities in many African countries, may have generated new opportunities and dynamics, and thus modified Africa's scientific collaborations, i.e. the patterns, bottom-up drivers as well as the role of regional 'zones' and hubs (Guns and Wang, 2017 , for a study on the networks of African collaborations).

\footnotetext{
${ }^{1}$ In addition of continental plans, the Economic Community of West African States (ECOWAS) and the Southern African Development Community (SADC) have adopted regional strategies for STI. More recently, the Science, Technology and Innovation Strategy for Africa (STISA-2024) has been adopted as the successor of the CPA (AUC, 2014) and in 2015 the establishment of the pan-African platform Alliance for Accelerating Excellence in Science in Africa, (AESA

http://www.nepad.org/programme/alliance-accelerating-excellence-science-africa-aesa).
} 
The aim of this paper is twofold: it analyses the determinants of scientific collaborations among African countries; it investigates the role of regional factors (e.g. regional 'communities') together with the influence of historical ties (e.g. Great Britain vs. France) in these collaborations and how they changed overtime. In line with earlier studies (Hoekman et al. 2010), we use bibliometric data on co-authorships to identify the patterns of scientific collaborations (Katz and Martin 1997). The remainder of the paper is organized as follows. Section 2 presents our main hypotheses. Section 3 describes the methodological approach, the dataset and variables. Section 4 presents and discuss the main results. Section 5 concludes.

\section{Main analytical hypotheses}

Several empirical studies using co-publications as a proxy for research collaborations have adopted the proximity approach ${ }^{2}$ to identify the patterns of scientific and technological collaboration across territories both in advanced and emerging economies (Cassi et al. 2015; Hardeman et al. 2015; Hoekman et al. 2010; Ponds et al. 2007; Montobbio and Sterzi, 2013).

Since the early 2000s, the scientific works dedicated to mapping and measuring the research output and impact of Africa using bibliometric data have flourished (among other, Arvanitis et al. 2000; Tijssen 2007; Boshoff, 2009, 2010; Toivanen and Ponomariov 2011; Mêgnigbeto 2013; Pouris and Ho 2014; Confraria and Godinho 2015; Sooryamoorthy, 2018). The current patterns and outputs of scientific collaborations in Africa clearly suggest that African countries are still far from exploiting the potential for synergies and complementarities between their research systems. Nevertheless, as the total scientific outcomes of the continent, research collaborations are slightly increasing in Africa and some signs of (local) growing self-reliance and changing local dynamics can be observed (Adams et al 2014, Guns and Wang 2017). Also, as underlined by the AOSTI (2014), more than 36 AU Member States have recorded increases in their intra-continental cooperation in the past decade. Earlier statistical and networks analyses suggest that such scientific activities rely upon common language, history and geographical "proximity" as key dimensions for collaboration (Mêgnigbeto 2013 for an overview of West African collaborations, Adams et al., 2014). Yet, as underlined by Adams et al. (ibid.), more research is needed to properly understand the complexity of African collaborations and the bottom-up and local drivers behind the Africa's scientific collaboration outcomes. Such evidence is needed for the design and implementation of policies targeting further regional scientific integration in Africa.

Accordingly, our analysis aims to assess and explain the existing degree of scientific integration of African countries. To do that, we perform an econometric analysis using essentially bibliometric to capture scientific collaborations. More specifically we test if:

1) Geographical distance is decreasing over time. In an integrated area, geographical distance should not in principle matter (Hoekman et al., 2010). Other determinants should prevail. So, a decreasing importance of the geographical distance effect in shaping scientific collaboration between African countries can be interpreted as a first evidence of an increasing integration or at least an intensification of collaboration network. In addition, the effect of geographical distance is also expected to be attenuated due, for instance, to improved information-sharing opportunities through internet, (air) mobility, facilitation of visa (upon arrival policies).

2) Legacy of common past colonial ties is decreasing over time. The historical legacy of past ties, especially the difference between Francophone and Anglophone countries, still matters for scientific collaboration between countries (Adams et al 2010, Boshoff, 2009, 2010 on central and southern Africa, Mêgnigbeto 2013 for West Africa). However, we should expect that this effect is decreasing over time as the integration effort is increasing.

2 Spatial scientometrics literature has distinguished five main types of proximities: geographical, institutional, cognitive, organisational and social (Boschma, 2005; Hardeman, et al. 2015, Frenken et al. 2009). 
3) Regional 'Community' effect is increasing. Established to facilitate the economic integration, the Regional Economic Communities (RECs) are closely integrated with the AU's work and have been increasingly involved in the coordination of AU's Member States in different areas. Thus and depending on the RECs, we can expect that they may have played a structuring and integrative role among the countries' research systems.

4) The role of non-African countries is decreasing. Usually, international collaboration with non-African countries can be interpreted as index of scientific quality, however a too high share of 'outside' collaboration "may denote a situation of dependence" (AOSTI, 2014) on, for instance, external resources (e.g. financial supporting funds). The emergence of African countries should entail a lower importance of external partners in shaping local collaborations.

\section{Methodology and data}

\subsection{Econometric approach}

In line with previous empirical studies, we model the co-publication patterns between any two countries using a gravity model (Ponds et al. 2007; Hoekman et al. 2010; Montobbio and Sterzi, 2013). The gravity approach, which has been initially exploited in the trade literature to explain inter-country trade flows (Bergstrand, 1985), takes inspiration from the Newtonian law of gravitation, where the attraction between two objects depends positively on their masses and negatively on their distance. In our conceptualisation, the model implies that the intensity of co-publication activity between two countries increases with their number of publications, which proxy their mass, and decreases with their distances (e.g. geographical). Our gravity model is represented by equation (1):

$$
\ln (\text { Copub })_{i j t}=\beta_{0}+\beta_{1} A_{i t}+\beta_{2} A_{j t}+\beta_{3} P R O X_{i j t}+\varepsilon_{i j t}(1)
$$

where $C o p u b_{i j t}$ is the natural $\log$ of the number of co-publications between countries $i$ and $j$, at time $t . A_{i t}$ and $A_{j t}$ respectively capture the masses (e.g. number of publications) of countries $i$ and $j$ at time $t$. We take the inverse of the distance (i.e. $P R O X$ ) to capture the different types of proximities between organisations: geographical, scientific, social, institutional.

We use a negative binomial to tackle the issues of skewed distribution, excess of zeros and over-dispersion in the co-publication data (Hilbe, 2011, Cameron and Trivedi, 2013). We mainly performed two sets of regressions. In the main set, the determinants of co-publications are explored mainly according to the hypotheses suggested in Section. An additional set of regressions aims at exploring the changes in the effects of the geographical distance and of 'having specific common partners', i.e. whether they belong to the political North or subsets or only to Africa. In this latter framework, twelve regressions are performed with dependent variables defined over 3 years, i.e. $\mathrm{t} / \mathrm{t}-2$; where $\mathrm{t}=2004 \ldots 2015$.

\subsection{Data and variables}

The main source of data $^{3}$ is the HCERES-OST scientific publication dataset, an enriched ${ }^{4}$ version of Thompson Reuters Web of Science - SCIENCE CITATION INDEX EXPANDED (henceforth WoS). Even if we have used an enriched version of WoS, our data suffers of the same drawbacks of the original data in terms of coverage ${ }^{5}$.

\footnotetext{
${ }^{3}$ Other source is the CEPII gravity dataset, cepii.fr.

${ }_{5}^{4}$ For instance, the geolocalisation of authors.

${ }^{5}$ A comprehensive comparison of WoS and Scopus (Mongeon and Paul-Hus,2016) shows that Scopus is subject to the same biases as WoS, in spite of its larger journal coverage. This bias is hard to avoid for international comparative studies but should be kept in mind when interpreting the results.
} 
We consider publications in 11 scientific fields ${ }^{6}$ on $2000-2015$, reporting among the authors' affiliation located in 52 African countries. ${ }^{7}$ This means that our sample concerns all publications involving at least an author located in Africa and that we have information on collaboration with authors are located out of the continent. Based on this, we can define a series of variables adapted to a gravity equation (Table 1). Time-variant explanatory variables are integrated with a 3 -years lag, i.e. t-1 to t-3. Table 2 gives the descriptive statistics.

Table 1 - Variables list and definition

\begin{tabular}{|c|c|}
\hline Variable & Definition \\
\hline Copub $_{\text {ijt }}$ & $\begin{array}{l}\text { Number of scientific papers co-authored by residents of countries } i \text { and } j \text { at } \\
\text { time } t\end{array}$ \\
\hline lang_off ii $_{\text {i }}$ & $i$ and $j$ share a common language (dummy) \\
\hline $\operatorname{comcol}_{\mathbf{i j}}$ & $i$ and $j$ have ever had a colonial link (dummy) \\
\hline $\operatorname{logdist}_{\mathrm{ij}}$ & $\begin{array}{l}i \text { and } j \text { geographical distance weighted by population of main agglomeration } \\
\text { (logarithm) }\end{array}$ \\
\hline logpastcopubijt & Stock of co-publication between country $i$ and $j$, time $t-1$ to $t-3$ (logarithm) \\
\hline $\operatorname{logpub}_{\text {it }}$ & Stock of publication of country $i$, time $t-1$ to $t-3$ (logarithm) \\
\hline rec $_{i j}$ & $i$ and $j$ belong to a same REC (dummy) \\
\hline CEN_SAD & $\mathrm{i}$ and $\mathrm{j}$ belong to a specific REC (dummy) \\
\hline dist_tech ${ }_{\mathrm{ijt}}$ & $\begin{array}{l}\text { The complement to } 1 \text { of cosine similarity of the scientific profiles of } \\
\text { country's } i \text { and } j \text {, time } t-1 \text { to } t-3 \text {. The scientific profile is proxied by the shares } \\
\text { of publications by field. }\end{array}$ \\
\hline
\end{tabular}

For each African country $i$ at year $t$, we calculate the stock of publications in the previous three years. Moreover, based on this stock, we map the scientific profile of the country in terms of the eleven fields. The same is done for each country for each of the eleven fields, i.e. we have calculated its stock and mapped its profile in terms of subfields. On this basis, the scientific proximity between two countries $i$ and $j$ is calculated as 1 minus the cosine similarity between the scientific profiles of the two countries.

For each couple of countries, $i$ and $j$, we have some relational variables, which are not varying over time, such as geographical distance from the capital cities (i.e. distance_geo $\mathrm{ij}_{\mathrm{ij}}$ ). The geographical distance has been transformed in proximity considering its inverse (i.e. geo prox $_{\mathrm{ij}}$ ). ${ }^{8}$ Moreover, we define a dummy if the two countries share a common past colonial tie, if they speak the same language and if they belong to a specific Regional Economic Community (REC_name ${ }_{i j}$ ). RECs are not exclusive, i.e. the same country can belong to one or more communities. The African union recognizes eight RECs including the Arab Maghreb Union (AMU, 5 countries), the Common Market for Eastern and Southern Africa (COMESA, 19), the Community of Sahel-Saharan States (CEN-SAD, 29), the East African Community (EAC, 5), the Economic Community of Central African States (ECCAS, 10), the Economic Community of West African States (ECOWAS, 15), the Intergovernmental Authority on Development (IGAD, 8) and the Southern Africa Development Community (SADC, 15) (see also at: https://au.int/en/organs/recs).

Moreover, for each dyad we calculate variables that can vary over time. The copublication is the count of the publications co-authored by two countries at time $t$ (i.e. copub $\left.\mathrm{ijt}_{\mathrm{ijt}}\right)$

6 Fundamental biology, Medical research, Applied biology, Chemistry, Physics, Earth Sciences, Astronomy and Astrophysics, Engineering and Computer Sciences, and Mathematics, Social sciences and Humanities, Multidisciplinary. They are defined as an aggregation of Thomson Reuters Scientific Categories.

${ }^{7}$ Gambia and South Sudan are excluded. Gambia's code was not available at the download and only 5 years are available for South Sudan. The country obtained its independence (from the North) since 2011.

${ }^{8}$ If the distance is zero then proximity is assumed to be equal to 1 . 
and past co-publications is the amount of publication co-authored by the two countries in the previous three years (i.e pastcopub $\mathrm{ijt}_{\mathrm{ijt}}$ and its logarithm: $\log$ pastcopub $\mathrm{b}_{\mathrm{ijt}}$ ).

Table 2 - Descriptive statistics

\begin{tabular}{cccccc}
\hline Variable & Nb obs & Mean & Std Dev & Minimum & Maximum \\
\hline copub & 20034 & 1.99 & 8.72 & 0.00 & 287.0 \\
\hline lang_off & 1431 & 0.44 & 0.50 & 0.00 & 1.00 \\
\hline comcol & 1431 & 0.26 & 0.44 & 0.00 & 1.00 \\
\hline CEN_SAD & 1431 & 0.28 & 0.45 & 0.00 & 1.00 \\
\hline COMESA & 1431 & 0.11 & 0.31 & 0.00 & 1.00 \\
\hline EAC & 1431 & 0.01 & 0.08 & 0.00 & 1.00 \\
\hline ECCAS & 1431 & 0.03 & 0.17 & 0.00 & 1.00 \\
\hline ECOWAS & 1431 & 0.07 & 0.26 & 0.00 & 1.00 \\
\hline IGAD & 1431 & 0.01 & 0.12 & 0.00 & 1.00 \\
\hline SADC & 1431 & 0.07 & 0.26 & 0.00 & 1.00 \\
\hline AMU & 1431 & 0.09 & 0.29 & 0.00 & 1.00 \\
\hline dist_tech & 1431 & 0.28 & 0.30 & 0.00 & 9.19 \\
\hline logdistw & 20034 & 8.04 & 0.65 & 5.09 & 10.36 \\
\hline logpub_i & 20034 & 5.28 & 2.34 & 0.00 & 10.36 \\
\hline logpub_j & 20034 & 4.91 & 2.26 & 0.00 & 6.43 \\
\hline logpastcopub & 20034 & 0.63 & 1.05 & 0.00 & \\
\hline
\end{tabular}

\section{Main empirical results}

Africa's relative share has almost doubled in 15 years to about $3.5 \%$ of world scientific co-publications in 2015. However, the continent still represents a very low share of the world scientific production, reflecting mainly the low number of researchers observed in this world's region (UNESCO 2015), the limited funding for STI activities as well as other economic and structural features (see for instance Irikefe et al 2011, AOSTI 2013). The greatest share of the upward trends in co-publications occur since the mid-2000s. This period also marks the adoption of the African S\&T Consolidated Plan of Action (CPA, 2006) as well as the establishment of the 2008 Protocol on Relations between the AU and the RECs and the Joint Africa-EU Strategy (JAES, end 2007) ${ }^{9}$.

Over all, the 52 African countries considered have produced about 460,324 distinct publications including 229,479 international co-publications. The important variability within the RECs mainly relates to the heterogeneous characteristics and endowments of the national science and research systems of the countries. This somehow also raises the issue of the relevance or ability of some of these geographical spaces to favour the regional scientific integration(s). As also underlined by previous works, major publishers include South Africa, Egypt, Nigeria and Cameroon, and Kenya (see also in Tijssen 2007, Pouris and Ho 2014). In terms of fields, the continent's publications are dominated by medical research (35\%). Representing about $15 \%$ each in African publications, the fields of Fundamental biology and Applied biology-ecology, come as the second most important ones. This pattern seems to hold true when looking at individual RECs, but for the Arab Maghreb Union in which the second top areas are Engineering and Chemistry, accounting for one fifth of the RECs publications each. ${ }^{10}$ In terms of international co-publications, South Africa, Egypt, Tunisia, Nigeria and

\footnotetext{
${ }^{9}$ See at https://ec.europa.eu/europeaid/regions/africa/continental-cooperation/joint-africa-eu-strategy en 10 See Sooryamoorthy (2018) who exploits Web of Science for a detailed mapping of African publications at the country and field levels on the period 2000-2015.
} 
Morocco, respectively, emerge as the most active countries. Among these countries, the role of South Africa and Nigeria as possible enablers of further integration has already been suggested by Toivanen and Ponomariov (2011). Outside Africa, the top five partners include the United States, France, UK, Germany and Saudi Arabia.

Table 3 shows our main estimation results. The results confirm that the co-publication intensity between two countries increases with their scientific masses, and decreases with geographical distances. Similarly, the further apart two countries are in terms of scientific profiles, the lower the intensity of co-publications can be expected.

Table 3 - Estimates

\begin{tabular}{lrrrrrr}
\hline \multicolumn{7}{c}{ Analysis Of GEE Parameter Estimates - Empirical Std Error Estimates } \\
\hline Parameter & Estimate & St. Error & \multicolumn{2}{c}{ 95\% Conf Lim } & Z & Pr $>|\mathbf{Z}|$ \\
\hline Intercept & -32.0372 & 5.8866 & -43.5747 & -20.4998 & -5.44 & $<.0001$ \\
\hline logpub_i & 0.2805 & 0.0125 & 0.2559 & 0.3051 & 22.36 & $<.0001$ \\
\hline logpub_j & 0.2869 & 0.0128 & 0.2618 & 0.3120 & 22.42 & $<.0001$ \\
\hline logdistw & -0.2864 & 0.0364 & -0.3578 & -0.2150 & -7.86 & $<.0001$ \\
\hline logpastcopub & 0.7217 & 0.0215 & 0.6796 & 0.7638 & 33.60 & $<.0001$ \\
\hline comcol & 0.2042 & 0.0376 & 0.1305 & 0.2779 & 5.43 & $<.0001$ \\
\hline dist_tech & -2.0749 & 0.1614 & -2.3913 & -1.7585 & -12.85 & $<.0001$ \\
\hline lang_off & 0.1689 & 0.0388 & 0.0929 & 0.2449 & 4.36 & $<.0001$ \\
\hline CEN_SAD & -0.1309 & 0.0513 & -0.2316 & -0.0303 & -2.55 & 0.0108 \\
\hline COMESA & -0.1783 & 0.0472 & -0.2709 & -0.0857 & -3.77 & 0.0002 \\
\hline EAC & 0.0780 & 0.1037 & -0.1253 & 0.2813 & 0.75 & 0.4523 \\
\hline ECCAS & 0.0938 & 0.0769 & -0.0569 & 0.2445 & 1.22 & 0.2224 \\
\hline ECOWAS & 0.2241 & 0.0779 & 0.0715 & 0.3767 & 2.88 & 0.0040 \\
\hline IGAD & 0.0441 & 0.0687 & -0.0906 & 0.1788 & 0.64 & 0.5214 \\
\hline SADC & 0.1041 & 0.0550 & -0.0036 & 0.2118 & 1.89 & 0.0583 \\
\hline UMA & -0.4095 & 0.0650 & -0.5368 & -0.2821 & -6.30 & $<.0001$ \\
\hline year & 0.0150 & 0.0029 & 0.0092 & 0.0207 & 5.10 & $<.0001$ \\
\hline
\end{tabular}

'Speaking the same language' also matters as suggested by earlier descriptive and mapping analyses (Mêgnigbeto 2013, Adams et al 2014). The positive effect of past copublications means that two countries are more likely to collaborate if they had previously collaborated. Indeed, future collaborations may beneficiate from existing communication channels (and even established routines) and frameworks (institutional, scientific, etc.). At the policy level, this might in turn be leveraged to support initial collaborations between nonpartner African countries with close research interests (scientific proximity matters) as it might facilitate sustained collaborations. Moreover, the analysis suggests that past colonial ties (France, United Kingdom, the Netherlands and Portugal) still influence significantly the intensity and patterns of co-publications of the African continent. Among them, France and UK rank as the second and third top non-African partners for co-publication.

The negative and significant impact of some RECs may reflect the high diversity within the communities in terms of scientific capability and maturity, and also a limited structuring role of some of them, once other determinants are controlled for. This is consistent with the high standard deviation ranges in the scientific production capacity of RECs. Rather than concluding that some RECs would hamper the development of scientific co-publications, our results suggest that the role of some RECs as integrative scientific areas can be questioned. Also, this can stimulate further research on the socio-institutional factors, that underpin scientific co-authorship in areas such as ECOWAS or SADC.

The dynamics analysis reveals that the geographical distance shows a decreasing effect. The lower importance of the geographical distance effect can signal further integration or greater international co-authorship networks. Besides, the possible impacts of greater institutional and policy support and availability of funding (or grants) possibilities for 
collaborative projects, this trend can also be related to the few improvements in the last decades in the air traffic in Africa as well as the higher penetration of internet and related software and applications. All together they facilitate regular (face-to-face) exchanges, meetings and easier communications for scientific collaborations and co-authorship.

Furthermore, having a 3rd common partner always increases the co-publication intensity. This holds true (i) it is an African country, (ii) even more when the third partner is from the political North (e.g. developed countries), and (iii) most importantly when this third partner is a former colony (i.e. France, United Kingdom, the Netherlands and Portugal). Finally, our explorations also suggest that involving out-of-the-continent partners has an increasing effect over time. These additional explorations confirm the influence of the global science on the publication patterns of the continent or that increasing convergence is taking place. In particular, this trend appears more accentuated since the end of the 2000s.

\section{Concluding remarks}

The rise of an 'African' collaborative science is still underway. Our study supports a multidimensional approach to strengthen the regional scientific integration. Indeed, further actions to improve the physical (air, road traffic and infrastructure) and connectivity (access to fast internet, to international and African knowledge sources and networks.) and social links across the continent (e.g. regular languages training and educational and cultural exchanges programs) may be explicitly combined with policy strategies for a collaborative science. Such support would contribute to attenuate the negative effects of geographical distance(s).

Moreover, the findings question the structuring and integrative role of some RECs with respect to scientific collaborations. Still, a few communities such as ECOWAS and SADC seem to yield a positive influence on the intensity of co-publications between members, once geographical distance, language and scientific proximity are accounted for (among other). Further studies should be undertaken in order to identify the specific drivers (e.g. role of a specific African country-hub) or potential 'good-practices' in these regional spaces.

Finally, even if bibliometrics can provide useful results and policy recommendations, it is worth pointing out that our analysis is only an indirect assessment of the initiatives promoted over a long time period. Bibliometric-based measures concern only production and dissemination of knowledge, grasping in this way only the output. Also, we rely on a somehow biased data set, because it includes mainly international journals in English. Therefore, we cannot capture fully the geography of regional collaborations, in particular if domestic co-publications are issued in African journals that are not listed in Web of Science.

\section{References}

Adams, J., Gurney, K., Hook, D., Leydesdorff, L. (2014), International collaboration clusters in Africa. Scientometrics, 98(1), 547-556.

Adams, J., King, C., Hook, D. (2010), Global research report: Africa. Thomson Reuters.

African Observatory of Science, Technology and Innovation (2014), Assessment of Scientific Production in the African Union, 2005-2010, Malabo: The AOSTI.

-, (2013), STI policy-making in Africa: An assessment of capacity needs and priorities. WP 2., Equatorial Guinea. Malabo: AOSTI.

African Union Commission, AUC (2014), AU Strategy for Science, Technology and Innovation for Africa 2024, STISA-2024, Addis Ababa: African Union.

Arvanitis, R., Waast, R., Gaillard, J. (2000). Science in Africa: A bibliometric panorama using PASCAL database. Scientometrics, 47, 457-473.

Bergstrand J.H. (1985), The Gravity Equation in International Trade: Some Microeconomic Foundations and Empirical Evidence, The Review of Econ. and Statistics, 67 (3), 474-81.

Boschma R. A. (2005), Proximity and innovation: a critical assessment, Reg Stu., 39 (1), 1-14. 
Boshoff, N. (2009), Neo-colonialism and research collaboration in Central Africa. Scientometrics, 81(2), 413-434.

Boshoff, N. (2010), South-South research collaboration of countries in the Southern African Development Community (SADC). Scientometrics, 84(2), 481-503.

Cameron, A.C., Trivedi, P. K. (2013), Regression Analysis of Count Data, 2nd edition, Econometric Society Monograph No.53, Cambridge University Press, 1998 (566 pages).

Cassi, L., Morrison, A., Rabellotti, R. (2015), Proximity and scientific collaboration: Evidence from the global wine industry, Tijdschrift voor economische en soc. Geo., 106(2), 205-19.

Confraria, H., Godinho, M. M. (2015). The impact of African science: A bibliometric analysis. Scientometrics, 102, 1241-1268.

German Development Institute, DIE (2010), African Developments: Higher Education and Research Capacities: Africa in the Globalising Knowledge Society. Briefing paper 13.

Dosso, M. et al. (2017), Research and Innovation, pp. 217-226, in EC, JRC (2017), Science for the AU-EU Partnership, Publications Office of European Union: Luxembourg, $320 p$.

Frenken, K., Hardeman, S., Hoekman, J (2009), Spatial scientometrics: towards a cumulative research program, Journal of Informetrics, 3(3), 222-232.

Guns, R., Wang, L. (2017), Detecting the emergence of new scientific collaboration links in Africa: A comparison of expected and realized collaboration intensities, Journal of Informetrics, 11(3), 892-903.

Hardeman, S., Frenken, K., Nomaler, Ö., Ter Wal, A. J. (2015), Characterizing and comparing innovation systems by different 'modes' of knowledge production: A proximity approach. Science and Public Policy, 42(4), 530-548.

Hilbe, J. (2011). Negative Binomial Regression. Cambridge: Cambridge University Press.

Hoekman, J., Frenken, K., Tijssen, R.J.W. (2010), Research collaboration at a distance, Research Policy, 39(5), 662-73.

Irikefe, V., Vaidyanathan, G., Nordling, L., Twahirwa, A., Nakkazi, E., Monastersky, R. (2011). Science in Africa: View from the front line. Nature, 474, 556-559.

Katz, J.S., Martin, B.R. (1997), What is research collaboration? Res. Policy, 26 (1), 1-18.

Mêgnigbêto, E. (2013), International collaboration in scientific publishing: the case of West Africa (2001-2010). Scientometrics, 96(3), 761-783.

Mongeon, P., Paul-Hus, A. (2016), The journal coverage of Web of Science and Scopus: A comparative analysis. Scientometrics, 106(1), 213-228.

Montobbio, F., Sterzi, V. (2013), The globalization of technology in emerging markets: a gravity model on the determinants of international patent collaborations. World Development, 44, 281-299.

NEPAD (2006), Africa's S\&T Consolidated Plan of Action. NEPAD, Pretoria, South Africa.

Ponds, R.H.F., Oort, F.G. van and Frenken, K. (2007), The geographical and institutional proximity of research collaboration, Papers in Regional Science, 86, 423-443.

Pouris, A., Ho, Y.-S. (2014). Research emphasis and collaboration in Africa. Scientometrics, 98, 2169-84.

Sooryamoorthy, R. (2018), The production of science in Africa: an analysis of publications in the science disciplines, 2000-2015, Scientometrics.

Tijssen, R. J. W. (2007). Africa's contribution to the worldwide research literature: New analytical perspectives, trends, and performance indicators. Scientometrics, 71, 303-327.

Toivanen, H., Ponomariov, B. (2011). African regional innovation systems: Bibliometric analysis of research collaboration patterns 2005-2009. Scientometrics, 88, 471-493.

UNESCO (2015), UNESCO Science Report: towards 2030, Paris, France.

World Bank, WB, (2014), A decade of development in Sub-Saharan African STEM research. Washington, DC: World Bank Group. 